\title{
Модели послевоенного восстановления городов: исторический опыт и уроки
}

\author{
М. И. Альсулейман, С. И. Яковлева $ه$ \\ Тверской государственный университет, Российская Федерация \\ (170021, г. Тверь, ул. Прошина, д. 3, корп. 2)
}

\begin{abstract}
Аннотация: Цель: обзор международного опыта для выявления основных моделей первоначального восстановления городов, разрушенных в годы Второй мировой войны. Города, районы и страны, пострадавшие от военных разрушений, сейчас принято называть конфликтными и постконфликтными (терминология ООН). Выполненное исследование исключительно актуально для современных конфликтных регионов, в том числе для Сирии, которая приступила к восстановлению столицы (Дамаск) и самого крупного и самого разрушенного города страны - Алеппо. Материалы и методы. Особенности послевоенного восстановления городов описаны в классических учебниках истории архитектуры и градостроительства, подтверждены документами и фотографиями. Карты с оценками разрушенной застройки городов Сирии представлены в атласе ООН (2019). Обширная исходная информация была систематизирована по ключевым географическим (пространственным) параметрам восстановления городов: планировочные особенности (форма плана и форма планировки с вариантами довоенного восстановления и перепланировки), плотность застройки и основные стили застройки. Предпринята попытка выявить основные пространственные модели постконфликтного восстановления городов. Результаты. Типология пространственных моделей восстановления городов представляет собой своеобразный градостроительный определитель для формирования концепции постконфликтного восстановления городов - «командных центров» национального и регионального расселения. Это дает возможность выбрать варианты восстановления с учетом национальной специфики градостроительства. $B b l в o d b l$ Типология моделей постконфликтного восстановления городов показала лишь отдельные типичные примеры, она открыта для дополнений. Главные уроки первичного восстановления городов Сирии уже можно определить, опираясь на международный опыт: первоочередное восстановление менее разрушенных жилых зданий, на расчищенных площадках - современные новостройки, восстановление и сохранение исторических центров городов, восстановление по новым генеральным планам (перепланировкой), в пригородах городов - строительство благоустроенных поселков для пресечения появления и роста неформальных поселений. Быстрого масштабного восстановления городов не будет. Восстановление исторических памятников отложено. По основным элементам - это немецкая модель восстановления (в Германии восстановление довоенного образа городов продолжается).
\end{abstract}

Ключевые слова: пространственные модели восстановления городов, реконструкция и реставрация городов, историческая застройка, восстановление городов Сирии.

Для цитирования: Альсулейман М.И., Яковлева С.И. Модели послевоенного восстановления городов: исторический опыт и уроки // Вестник Воронежского государственного университета. Серия: География. Геоэкология, 2020, № 2, c. 40-45. DOI: https://doi.org/10.17308/geo.2020.2/2884

\section{ВВЕДЕНИЕ}

Проблемы послевоенного восстановления расселения (городов и сельских пунктов) стран и регионов - достаточно популярная тема в СМИ, в том числе масса фотографий, воспоминаний, ис- торических и современных фактов, экспертных оценок. Монографии, учебные издания и статьи, как правило, инженерно-строительного и архитектурного содержания, иногда - исторические, социологические, культурологические, геополитические.

() Альсулейман М.И., Яковлева С.И., 2020

E-mail: sv yakowleva@mail.ru

Контент доступен под лицензией Creative Commons Attribution 4.0 License. 
Для географических исследований наибольший интерес представляют пространственные аспекты восстановления городов: перепланировка городов или ее сохранение с расширением каркасных линий (магистральных улиц, проспектов) и узлов, разуплотнение исторических центров, связи с гидрографическим осями, планы восстановления городов вместе с пригородами. Сохранение исторического центра и его застройки - это сохранение устойчивости ядра планировочной структуры растущего города. Восстановление разрушенной исторической застройки - это восстановление утраченного облика старого города и его туристского образа.

В данной статье на базе обобщения опыта восстановления посткризисных городов предпринята попытка разработки рекомендаций для восстановления городов Сирии - главных элементов расселения страны, регионов и районов.

\section{МЕТОДЫ ИССЛЕДОВАНИЯ И РЕЗУЛЬТАТЫ}

Для обобщения опыта восстановления разрушенных городов обращаемся к истории послевоенного возрождения городов Европы и России (б. СССР), пострадавших в ходе Второй мировой войны. Рассматриваются наиболее разрушенные города, потерявшие до 80-95 \% жилого фонда. Исследование ограничено только характерными примерами городов, которые восстанавливались разными способами. Расширение этого «каталога» городов может в дальнейшем позволить сделать выводы о территориальной (географической) их структуре по вариантам послевоенного восстановления.

По литературным источникам [3] составлены краткие характеристики городов, пострадавших во Второй мировой войне. Основные параметры для сравнения городов: масштабы разрушений, наличие планов восстановления и общая продолжительность восстановительных работ.

1. Варшава, Польша (84\% города было разрушено). Довоенный город развивался без плана. Разработан план реконструкции Варшавы и создано «Бюро восстановления столицы». Восстановление продолжалось до 1970-х годов. Исторический центр был восстановлен (воссоздан) очень быстро.

2. Дрезден, Германия (б. ГДР). Потери: уничтожено $23 \%$ индустриальных строений, $56 \%$ нежилых и неиндустриальных строений и примерно $50 \%$ жилой зоны. Город не имел точного плана реконструкции. Обломки исторических построек были собраны и сохранены (за городом), а конст- рукции разрушенных зданий оставили нетронутыми. Сразу после войны восстанавливались только отдельные здания. Восстановление города заняло более 50 лет. С 1990 года после объединения Германии началось активное восстановление исторического облика (главных исторических зданий) старого города по старым чертежам.

3. Минск. Разрушено 89 \% всех довоенных построек (осталось 70 неразрушенных зданий). Первому послевоенному генеральному плану Минска, составленному в конце 1946 года, был рекомендован снос большей части разрушенных зданий и строительство нового города. Восстановлен к концу 1950-х годов.

4. Калининград, разрушено $90 \%$, в том числе исторический центр, пригороды не пострадали. Восстановление бывшего Кенигсберга не было системным, началось с 1947 года, периодически менялась политика восстановления немецких исторических зданий. Масштабная перестройка началась с 1950 года.

5. Кельн, Германия, потери - $95 \%$. Из всех храмов уцелел лишь знаменитый Кельнский собор, который пострадал частично. Восстановление города шло все 1950-е и 1960-е годы. Многие здания и мосты были воссозданы в своем первоначальном облике.

6. Мюнхен, Германия, потери - $42 \%$. Городской совет Мюнхена в августе 1945 года принял решение о восстановлении, ориентированном на традиции. Ядро города должно было быть воссоздано в форме, которая была бы очень похожа на его довоенный облик, работы проведены в19451960 годы.

7. Берлин, Германия. При разделе Берлина вся историческая часть города оказалась в восточном секторе. Максимальные потери в центре города: там были разрушены 80 \% строений. Немцами разработаны планы для восстановления Восточного и Западного Берлина. Восстановление столицы затянулось до 1980-х годов. В Западном Берлине возникла необходимость полной перепланировки города с использованием современной архитектуры. В Восточном Берлине, где социалистическое государство выделяло на реконструкцию гораздо меньшие средства, на некоторых зданиях до сих пор видны следы осколков и пуль.

Варианты и модели восстановления разрушенных войной городов Европы и б. СССР различаются подходами к их возрождению: 1) послевоенное восстановление старого города (довоенной застройки) или 2) строительство нового города 
Основные пространственные модели первичного восстановления разрушенных городов

[Table. The main spatial models of the primary restoration of destroyed cities]

\begin{tabular}{|c|c|c|}
\hline $\begin{array}{c}\text { № } \\
\text { [No.] }\end{array}$ & $\begin{array}{l}\text { Модели восстановления разрушенных городов } \\
\text { (сразу после войны) } \\
\text { [Models for the restoration of destroyed cities } \\
\text { (immediately after the war)] }\end{array}$ & $\begin{array}{c}\text { Примеры восстановленных } \\
\text { городов* } \\
\text { [Examples of restored cities] }\end{array}$ \\
\hline 1 & Восстановление отдельных исторических зданий & Дрезден, Берлин \\
\hline 2 & $\begin{array}{l}\text { Исторический центр не восстанавливался, на его } \\
\text { месте - новая (современная) застройка. } \\
\text { Сохранились пригороды со старой застройкой. }\end{array}$ & $\begin{array}{l}\text { Калининград } \\
\text { (б. Кенигсберг) } \\
\text { Роттердам }\end{array}$ \\
\hline \multirow[t]{2}{*}{3} & $\begin{array}{l}\text { Восстановление старого города, в том числе } \\
\text { исторического центра }\end{array}$ & $\begin{array}{l}\text { Варшава и Гданьск, Тарту, } \\
\text { Кельн, Воронеж, Ростов- } \\
\text { на-Дону }\end{array}$ \\
\hline & $\begin{array}{l}\text { Восстановление разрушенных дворцово-парковых } \\
\text { комплексов }\end{array}$ & $\begin{array}{l}\text { Пригороды Ленинграда } \\
\text { (СПб.) }\end{array}$ \\
\hline 4 & $\begin{array}{l}\text { Умеренно консервативная модель: } \\
\text { восстановление исторического центра и новая } \\
\text { (современная) застройка города }\end{array}$ & Калинин (Тверь), Мюнхен \\
\hline 5 & $\begin{array}{l}\text { Полная перестройка города (планировочная } \\
\text { реконструкция города) }\end{array}$ & $\begin{array}{l}\text { Минск, Сталинград } \\
\text { (Волгоград), } \\
\text { Большой Лондон (переход } \\
\text { от планирования города } \\
\text { к районной планировке) }\end{array}$ \\
\hline
\end{tabular}

*Курсивом выделены города первоочередного восстановления. Всего в списке было 15 городов СССР. Источник: Постановление Совнаркома СССР от 1 ноября 1945 г. № 2722 «О мероприятиях по восстановлению разрушенных немецкими захватчиками городов РСФСР: Смоленска, Вязьмы, Ростова-на-Дону, Новороссийска, Пскова, Севастополя, Воронежа, Новгорода, Великих Лук, Калинина, Брянска, Орла, Курска, Краснодара и Мурманска». Государственный архив Российской Федерации. Ф. Р-5446. Оп. 106. Д. 165. Л. 71-86, 88. Документ открыт для просмотра на сайте: http://kosygin.rusarchives.ru/ postanovlenie-snk-sssr-no-2722-o-meropriyatiyah-po-vosstanovleniyu-razrushennyh-nemeckimi.

(современной застройки) на старом месте с расширением площади и коренной перепланировкой. Внимание в исследовании акцентируется на начальном (раннем) этапе восстановления после войны (1945-1950). Основные параметры сравнения моделей восстановления городов: технические вопросы восстановления и градостроительные, в том числе планировочные изменения города: форма планировки по рисунку улиц, расширение магистральных улиц и площадей, формирование исторического центра, функциональное зонирование городской территории.

Описание основных моделей послевоенного восстановления городов (таблица).

1. Восстановление отдельных исторических зданий. Примеры городов: Дрезден, Берлин: в городах разобрали завалы, расчистили и восстановили дороги, руины зданий оставили без восстановления. Этот отложенный во времени вариант восстановления позволил сосредоточиться на новостройках, к восстановлению исторической зас- тройки приступили через десятилетия, работы продолжаются сейчас на старых (исторических) местах. Эта модель очень длительная с постепенным восстановлением наиболее ценных исторических зданий/памятников.

2. Исторический иентр не восстанавливался, на его месте - новая (современная) застройка. Сохранились пригороды со старой застройкой. Примеры: Калининград (б. Кенигсберг) и Роттердам. Исторический центр города с разрушенной войной застройкой уничтожен (Калининград) - здания были разобраны на кирпичи и отправлены в другие города страны. В центре города были построены современные здания. Калининград утратил исторический центр. Неразрушенными остались окраины бывшего немецкого города. В городе были восстановлены лишь отдельные исторические здания, активное восстановление начато только в 1990 году.

3. Восстановление старого города, в том числе исторического центра. Примеры: Варшава и 
Гданьск (Польша), Тарту (Эстония), Воронеж, Ростов-на-Дону (Россия). В городах сразу приступили к восстановлению разрушенной застройки и достаточно быстро восстановили старые центры (довоенную застройку) - заново построили по старым планам, схемам и картинам. Новая застройка - за пределами исторического центра. Восстановлен исторический образ города. Пример восстановления городов как объектов историко-культурного наследия: Ленинград и его пригороды: Пушкин, Павловск, Петродворец, Урицк, Зеленогорск, Колпипо, Сестрорецк. В кратчайшие сроки (19451951) выполнены уникальные ремонтно-реставрационные работьл по восстановлению разрушенных дворцово-парковых комплексов в пригородах Ленинграда.

4. Умеренно консервативная модель: восстановление исторического центра и новая (современная) застройка города. Примеры: Калинин (Тверь) и Мюнхен. Особая «мюнхенская» модель с быстрым воссозданием разрушенного исторического центра, перепланировкой и современной застройкой за пределами исторического центра (сохранение исторического облика и старого туристского образа города).

5. Полная перестройка города (планировочная реконструкция города). Примеры: Минск, Сталинград (Волгоград). Новый город на старом месте с современной застройкой, полной или частичной перепланировкой города. При этом воссоздана транспортно-проблемная планировка «старых» городов: Минск (Белоруссия) получил радиальнокольцевую планировку. Только Сталинград (Волгоград) сформировал линейную планировку по Волжской оси с функциональными зонами, крупными кварталами и выходом центра города на берег Волги. Пример перехода от планирования города к районной планировке: Большой Лондон восстановление сильно разрушенного Лондона и Лондонского графства (работы Патрика Аберкромби в соавторстве с Форшоу). Это модель коренной перестройки города вместе с его центром и периферией, создание делового центра и функциональное районирование города.

От обзора опыта восстановления разрушенных городов переходим к рекомендациям - урокам, которые исключительно актуальны для современных постконфлитных районов. Наш пример - Сирия. Масштабы потерь в Сирии в период активных боевых действий (2011-2017) оцениваются как катастрофические. Актуальные оценки масштабов разрушений в городах Сирии отражены в атласе, под- готовленном под эгидой ООН (март 2019 г.) [4]. Масштабы разрушения городов значительные. При этом ущерб оценивается от минимального (5-30\% застройки), до высокого уровня - (до $75 \%$ ) и очень большого, когда на месте зданий остаются только руины. В нашей работе [2] предложена авторская методика оценки пространственных потерь в разрушенных городах: оценивалась степень разрушения пространственных элементов каждого города - центра, секторов (районов) и пригородов. Это позволило получить географическое (пространственное) представление о разрушениях единого городского пространства и не пострадавших частях города и окрестностей. Восстановление городов Сирии началось с расчистки дорог, разрушенные здания и целые кварталы только начинают постепенно восстанавливать. Люди живут везде, где можно жить, для новостроек расчищаются отдельные кварталы (участки) города, разрушенные храмы и мечети начали восстанавливать на средства прихожан.

Попытаемся определить главные уроки для политики восстановления разрушенных городов Сирии.

1. Системный последовательный характер восстановления городов (без кардинальной смены политики с разрушением «новостроек»).

2. Определение исторических элементов застройки для их последующего восстановления (в том числе с консервацией руин/конструкций и сохранением исторического места, его долговременной пространственной функции «памятного места»).

3. В современной застройке сохранять сирийский колорит (как правильно отмечают сирийские специалисты: восстанавливать города на «сирийской основе»). Избегать доминирование типовой застройки и только современного архитектурного стиля зданий.

4. При восстановлении городов создавать благоустроенные пригородные поселки, не порождая стихийного появления незаконных поселений и трущоб.

Жилищное строительство и реконструкция городов - приоритет первого и последующих этапов возрождения Сирии, ее расселения, в том числе восстановление довоенного уровня людности [1]. Сирийский вариант восстановления городов пытается сохранить национальный арабский тип города, но без традиционных трущоб. Для этого генпланы городов предполагают строительство пригородных поселков. В городах восстановление начинается на отдельных наиболее разрушенных 
участках, сносятся все руины, площадки очищаются от завалов и мусора, начинается строительство современных зданий. Специалисты разных стран мира разрабатывают генпланы восстановления городов Сирии, в том числе с перепланировкой. На необходимость восстановления исторической застройки (памятников архитектуры древних городов) настаивают ученые всего мира, помощь предлагает ООН.

Считаем важным акцентировать внимание на восстановление территориальной (географической) структуры расселения - не только каждого города и сельского населенного пункта, но и главных осей расселения - наиболее крупных городов, связанных дорогами [1], а также систем расселения вокруг базовых (опорных) центров городского и сельского расселения.

\section{ЗАКЛЮЧЕНИЕ}

Опыт восстановления разрушенных войнами городов показывает разные варианты политики по отношению к утерянным историческим центрам, старой застройке. Разрушенные города - объекты быстрого и/или долговременного, в том числе «отложенного», во времени восстановления (реставрации, реконструкции). Модели восстановления городов носят ретроспективный характер с попыткой воссоздать утерянный образ старого города и/ или новаторский. В первоначальный момент восстановления (раннее восстановление) приходится принимать сложные планировочные решения - начинать коренную перестройку города и его пригородов.

Ранние модели восстановления разрушенных городов (сразу после войны) можно свести в свое- образный ранжированный ряд с усложнением планировочной задачи восстановления (перестройки): от восстановления отдельных исторических зданий или старого центра города до полной перестройки города (планировочная реконструкция города) вместе с окрестностями.

Исторический опыт дает уроки, которые актуальны для современных стран/регионов, пострадавших от конфликтных и природных стихийных ситуаций.

\section{СПИСОК ЛИТЕРАТУРЫ}

1. Альсулейман М.И. Особенности расселения Сирии // Вестн. Твер. гос. ун-та. Сер. «География и геоэкология», 2017, № 2, с. 33-42.

2. Альсулейман М.И. Пространственное представление о разрушенных городах Сирии // Вестн. Удмуртского ун-та. Сер. Биология. Науки о земле, 2019, т. 29, № 4, c. 497-503.

3. Булинина Н.С. География жилой застройки в Нижнем Новгороде в прошлом и настоящем // Вестник Воронежского государственного университета. Сер. География. Геоэкология, 2014, № 1, с. 57-63.

4. Syrian cities damage atlas. Eight year anniversary of the Syrian civil war. Thematic assessment of satellite identified damage. 16 March 2019. Available at: https:// reliefweb.int/sites/reliefweb.int/files/resources/ reach_thematic_assessment_syrian_cities_damage_atlas_ march_2019_reduced_file_size_1.pdf?fbclid=IwAR3swXL n9ja8e1OW0y2WcoKurMiUNu5gXPovGwrNBDslqKD0e UbxddQyIe4 (accessed 10.11.2019).

Конфликт интересов: Авторы декларируют отсутствие явных и потенциальных конфликтов интересов, связанных с публикацией настоящей статьи.

Поступила в редакиию 28.11.2019

Принята к публикачии 02.06.2020

\title{
City Restoration Models: Historical Experience and Lessons
}

\author{
M. I. Alsuleyman, S. I. Yakovleva ${ }^{\bowtie}$ \\ Tver State University, Russian Federation (3, bldg. 2, Proshina St., Tver, 170021)
}

Abstract: Purpose: a review of international experience to identify the main models of the initial restoration of cities destroyed during the Second World War. Cities, regions and countries affected by military destruction are now called conflict and post-conflict (UN terminology). The study is extremely relevant for

(C) Alsuleyman M.I., Yakovleva S.I., 2020

$\triangle$ E-mail: sv yakowleva@mail.ru

The content is available under Creative Commons Attribution 4.0 License. 
modern conflict regions, including Syria, which has begun to rebuild the capital (Damascus) and the largest and most destroyed city in the country-Aleppo. Materials and methods. Features of the post-war reconstruction of cities are described in the classic textbooks on the history of architecture and urban planning, confirmed by documents and photographs. Maps with assessments of the destroyed buildings of Syrian cities are presented in the UN Atlas (2019). Extensive initial information was systematized according to the key geographical (spatial) parameters of urban restoration: planning features (a plan form and a planning form with options for pre-war restoration and redevelopment), building density and basic building styles. An attempt was made to identify the main spatial models of post-conflict reconstruction of cities. Results. The typology of spatial models for the restoration of cities is a kind of urban development determinant for the formation of the concept of post-conflict reconstruction of cities - the "command centers" of national and regional settlement. This makes it possible to choose the options of restoration, taking into account the national specifics of urban planning. Findings. The typology of models of post-conflict reconstruction of cities showed only a few typical examples, it is open for additions. The main lessons of the initial restoration of Syrian cities can already be determined on the basis of international experience: priority restoration of less destroyed residential buildings, modern buildings on restoration sites, restoration and preservation of historic city centers, restoration according to new master plans (redevelopment), construction in urban suburbs well-maintained villages to curb the emergence and growth of informal settlements. There will be no rapid large-scale restoration of cities. The restoration of historical monuments has been postponed. In terms of basic elements, this is the German reconstruction model (in Germany, the restoration of the pre-war image of cities is ongoing).

Key words: spatial models of urban restoration, reconstruction and restoration of cities, historical development, restoration of Syrian cities.

For citation: Alsuleyman M. I., Yakovleva S. I. City Restoration Models: Historical Experience and Lessons. Vestnik Voronezskogo gosudarstvennogo universiteta. Seria Geografia. Geoekologia, 2020, No. 2, pp. 40-45. (In Russ.) DOI: https://doi.org/10.17308/geo.2020.2/2884

\section{REFERENCES}

1. Al'suleyman M. I. Osobennosti rasseleniya Sirii [Features of Syria settlement]. Vestn. Tver. gos. un-ta. Ser. "Geografiya i geoekologiya”, 2017, no. 2, pp. 33-42. (In Russ.).

2. Al'suleyman M. I. Prostranstvennoye predstavleniye o razrushennykh gorodakh Sirii [Spatial view of the destroyed cities of Syria]. Vestn. Udmurtskogo un-ta. Ser. Biologiya. Nauki o zemle, 2019, v. 29, no. 4, pp. 497-503. (In Russ.).

3. Bulinina N.S. Geografiya zhiloy zastroyki v Nizhnem Novgorode v proshlom i nastoyashchem [Geography of residential buildings in Nizhny Novgorod in the past and present]. Vestnik Voronezskogo gosudarstvennogo univer-

\section{Яковлева Светлана Ивановна}

доктор экономических наук, кандидат географических наук, доцент, профессор кафедры туризма и природопользования Тверского государственного университета, г. Тверь, Российская Федерация, ORCID: https://orcid.org/0000-0002-7760-4553, e-mail: Sv Yakowleva@mail.ru

\section{Альсулейман Мохаммад Исса}

выпускник Дамасского университета (САР), магистратуры кафедры социально-экономической географии и территориального планирования Тверского государственного университета(2017), аспирант кафедры социальноэкономической географии и территориального планирования Тверского государственного университета, ORCID: https://orcid.org/0000-0002-9493-7392, e-mail: mhsh.ush@ya.ru siteta. Ser. Geografia. Geoekologia, 2014, no. 1, pp. 5763. (In Russ.).

4. Syrian cities damage atlas. Eight year anniversary of the Syrian civil war. Thematic assessment of satellite identified damage. 16 March 2019. Available at: https:// reliefweb.int/sites/reliefweb.int/files/resources/ reach_thematic_assessment_syrian_cities_damage_atlas_ march_2019_reduced_file_size_1.pdf?fbclid=IwAR3swXL n9ja8e1OW0y2WcoKurMiUNu5gXPovGwrNBDslqKD0e UbxddQyIe4 (accessed 10.11.2019).

Conflict of interests: The authors declare no information of obvious and potential conflicts of interest related to the publication of this article.

Received: 28.11.2019

Accepted: 02.06.2020

Svetlana I. Yakovleva

Dr. Sci. (Econ.), Cand. Sci. (Geogr.), Associate Professor, Professor of the Department of Tourism and Nature Management of Tver State University, Tver, Russian Federation, ORCID: https://orcid.org/0000-0002-7760-4553, e-mail: $\underline{\text { Sv Yakowleva@mail.ru }}$

Alsuleyman Mohammad Issa

Graduate of Damascus University (Syria), Master's degree in the Department of Socio-Economic Geography and Territorial Planning of Tver State University (2017), Postgraduate student of the Department of Socio-Economic Geography and Territorial Planning of Tver State University, ORCID: https://orcid.org/0000-0002-9493-7392, e-mail: mhsh.ush@ya.ru 